\title{
Effects of Different Breakfast Cereals on Alertness and Wellbeing
}

\author{
Andrew P. Smith ${ }^{1}$ \\ ${ }^{1}$ Centre for Occupational and Health Psychology, School of Psychology, Cardiff University, 63 Park Place, \\ Cardiff CF10 3AS, UK \\ Correspondence: Andrew P. Smith, Centre for Occupational and Health Psychology, School of Psychology, \\ Cardiff University, 63 Park Place, Cardiff CF10 3AS, UK. E-mail: smithap@ cardiff.ac.uk
}

Received: August 2, 2019 Accepted: August 23, $2019 \quad$ Online Published: September 16, 2019

doi:10.5539/jfr.v8n5p82

URL: https://doi.org/10.5539/jfr.v8n5p82

\begin{abstract}
Rationale: Previous studies have shown that there are established methodologies that can demonstrate differences between having no breakfast and consuming ready-to-eat cereals (RTEC). Much of this research has used high carbohydrate cereals (e.g. cornflakes) or high fibre cereals (e.g. wheat bran) and the present study extended this research by comparing cereals with different nutrients with a no breakfast condition.

Objectives: The main objective of the study was to compare breakfast cereal conditions differing in type of grain and the presence of $2 \mathrm{~g}$ inulin, over a 14 day period.

Methods: The study involved a 14 day intervention where the participants (adults and primary school children) were assigned to either a no breakfast condition, a Rice Krispie breakfast condition or a Multi-grain condition with $2 \mathrm{~g}$ of inulin. Questionnaires measuring aspects of wellbeing and ratings of alertness were completed at baseline and days 7 and 14 .

Results: Participants in the breakfast conditions reported lower scores than the no breakfast group for depression, anxiety, emotional distress, fatigue, cognitive difficulties, somatic symptoms, and digestive symptoms. These effects were observed across different cereals, in both children and adults, and were significant in both weeks. Differences between the cereal conditions were not observed in the wellbeing outcomes but the cereal with inulin was associated with increased alertness at day 14 .

Conclusions: Consumption of RTEC is associated with better wellbeing. These effects appear to be consistent across different products, age groups and over time. In contrast, a Multi-grain cereal with added inulin was, compared to Rice Krispies, associated with greater alertness at the end of the study which could plausibly be due to changes in gut bacteria.
\end{abstract}

Keywords: alertness, wellbeing, breakfast cereal, insulin, oligofructose, inulin

\section{Introduction}

There has been extensive research on the associations between eating breakfast and wellbeing (see Smith, 2018 for a review). In many of these studies the nature of breakfast has varied considerably, and it is often unclear whether breakfast is beneficial or whether skipping breakfast has negative effects. Smith (2018) examined the behavioural effects of eating a high carbohydrate breakfast cereal, namely cornflakes. The aim of this research was to identify sensitive outcome measures that could then be used to assess the effect of breakfast type and characteristics of the person eating it. The main objective of the present study was to extend this research by investigating the effects of two other breakfast cereals and comparing them to a no breakfast condition. A second aim was to compare the two cereals to determine whether their ingredients led to different behavioural effects. One line of research has focused on the fibre content of RTEC (Smith, Bazzoni, Beale, Elliott-Smith, \& Tiley, 2001). The results demonstrated that consumption of cereals high in fibre led to increased mental energy. A two week intervention study showed that eating high fibre breakfast cereal led to reduced fatigue. It was suggested that these results reflected improved digestion. Smith $(2010 \mathrm{a}, 2011)$ carried out secondary analyses of a large general population database (Smith, Johal, Wadsworth, Davey Smith, \& Peters, 2000) and found that digestive symptoms were related to reduced wellbeing (Smith, 2010a, 2011). These results are consistent with research that has shown impaired cognitive function in people with irritable bowel syndrome (Berrill et al., 2013; Kennedy et al., 2014). Further analyses demonstrated that the benefits of consuming a high fibre diet did not reflect fewer digestive problems (Smith, 2010a). Another possible mechanism was that wheat bran stimulates 
good bacteria in the colon which might then produce behavioural changes. However, the hypothesis that wheat bran is a prebiotic has not been supported (Smith, Deaville, \& Gibson, 2018) but this research led to investigation of established prebiotics (e.g. inulin) which are often added to other food products.

Inulin is found in many plants such as onions, leeks, garlic, artichokes and chicory. It is added to certain foods to replace carbohydrates or fats, increase fibre, or as a prebiotic (Gibson, Beatty, Wang, \& Cummings, 1995; Roberfroid, 2007). It is often combined with oligofructose, and research has often used this combination. Oligofructose-enriched inulin (Orafti®Synergy1) consists of chicory-derived inulin enriched by a specific fraction of oligofructose, produced by partial hydrolysis of chicory inulin in about a 50/50 ratio. Smith (2005) conducted a two week intervention study using $10 \mathrm{~g}$ of oligofructose-enriched inulin compared to a maltodextrin placebo. Inulin did not improve mood, well-being or performance but was associated with an increase in digestive problems (wind, feeling bloated and stomach cramps). It is likely that any beneficial prebiotic effects may have been negated by the increased digestive problems. Smaller doses $(2 \mathrm{~g})$ are added to food and there is evidence that these smaller doses may have beneficial behavioural effects especially when combined with carbohydrate. Smith, Sutherland and Hewlett (2015) compared the effects of $5 \mathrm{~g}$ inulin combined with food with placebo and found beneficial effects on digestion, memory and mood over a 4 hour testing period. Another study (Smith, 2019) used a larger dose (13g) of inulin over a longer time period (12 hours). The results showed increased digestive symptoms, a more negative mood and impaired memory after ingesting inulin.

In order to eliminate negative effects due to increased digestive problems, the present study examined the effects of an inulin supplement $(2 \mathrm{~g})$ in a commercially available breakfast cereal. This test cereal was compared with "Rice Krispies" which had a similar nutritional composition and a "no breakfast" condition. The design of this second study was similar to that used by Smith (2005) and the duration was 14 days which is a long enough time period to demonstrate effects of any changes in gut flora. The outcome measures consisted of questionnaires used by Smith et al. (2001) and Smith (2010b) to examine the effects of wheat bran and other types of breakfast cereal. In addition, ratings of alertness were made using visual analogue scales before and after breakfast. The study of wheat bran and other research on the effects of breakfast showed that alertness is increased by regular consumption of high fibre breakfast, as seen in pre-breakfast ratings, and acutely by breakfast consumption, as revealed by post-breakfast ratings.

The main objective of the present study was to compare RTEC meals with a no breakfast condition, and to identify cereal-specific differences. This was done using adults and children and effects were investigated over time. Measures included general wellbeing and ratings of alertness at specific times. This approach aimed to identify behavioural changes which could then form the basis for further research identifying underlying mechanisms and where microbiological assays of gut flora are required, and other indicators of prebiotic metabolites measured.

\section{Methods}

The study was approved by the ethics committee, School of Psychology, Cardiff University, and carried out with the informed consent of the volunteers. Consent was given by the Head Teacher who agreed that the school would take part before any parents were approached. Consent was then obtained from each adult from each family and from one adult from each family on behalf of their child or children.

\subsection{Design}

A between groups design was used with the volunteers consuming the different breakfast cereals (or no breakfast) for two weeks. All members of the same family were assigned to the same breakfast condition.

\subsection{Recruitment Procedure}

Recruitment consisted of an advertisement for participants in school newsletters. Those who responded and fulfilled the inclusion and exclusion criteria (see below) were recruited. Recruitment continued until the required number of participants were obtained. The participants were recruited from primary schools in Cardiff. Parent and child volunteers were assigned to either the Rice Krispies (food name: toasted rice cereal), Multigrain (food name: Sweetened Multi-grain cereal shapes with natural prebiotic), or the no breakfast condition. They received an honorarium of $£ 50$ per individual taking part, and each school also received a single honorarium of $£ 150$.

At the start of the study, each family was given an opportunity to try the available cereals. Nobody taking part in the study was expected to eat a cereal or abstain from breakfast if that was not acceptable to them. Those interested in taking part completed a simple screening questionnaire over the telephone to check the exclusion/inclusion criteria before being entered into the study. 


\subsubsection{Exclusion Criteria}

Exclusion criteria were: (a) existing disease or use of long term medication (b) heavy smoking ( $>10$ cigarettes a day - this applied to adult participants only) (c) alcohol consumption above 20 units a week (for female adults) and above 30 units a week (for male adults), and (d) relevant food allergies.

\subsubsection{Inclusion Criteria}

Participants had to either be (a) willing to consume the allocated breakfast cereal every day for two weeks or (b) willing to abstain from eating breakfast for two weeks. In addition, children had to attend primary school, and each participating family had to consist of at least one eligible adult and one eligible child.

\subsection{The Final Sample}

Table 1 shows the number of adults and children in each condition and gender and age characteristics.

Table 1. Adults and children in each breakfast condition

\begin{tabular}{lllll}
\hline & No breakfast & Rice Krispies & Multigrain & Total \\
\hline Adults (N) & 37 & 64 & 59 & 150 \\
Males (N) & 15 & 29 & 25 & 69 \\
Age (mean; S.D.) & $37.2(7.0)$ & $39.0(8.0)$ & $37.6(8.2)$ & \\
Children & 34 & 63 & 53 & 150 \\
Males (N) & 17 & 31 & 34 & 82 \\
Age (mean; S.D.) & $9.2(2.0)$ & $8.0(1.9)$ & $7.9(2.1)$ & \\
Total & 71 & 127 & 112 & 300 \\
\hline
\end{tabular}

\subsection{The Two Cereals}

The ingredients of the two cereals are shown in Table 2.

Table 2. Nutrient composition of the two cereals (per 100g)

\begin{tabular}{lll}
\hline & Rice Krispies & Multi-grain \\
\hline Energy & $381 \mathrm{kcal}$ & $370 \mathrm{kcal}$ \\
Protein & $6 \mathrm{~g}$ & $8 \mathrm{~g}$ \\
Carbohydrate & $87 \mathrm{~g}$ & $77 \mathrm{~g}$ \\
of which sugars & $10 \mathrm{~g}$ & $18 \mathrm{~g}$ \\
of which starch & $77 \mathrm{~g}$ & $59 \mathrm{~g}$ \\
Fat & $1 \mathrm{~g}$ & $2.5 \mathrm{~g}$ \\
Fibre & $1 \mathrm{~g}$ & $8 \mathrm{~g}$ \\
Sodium & $0.65 \mathrm{~g}$ & $0.15 \mathrm{~g}$ \\
Salt & $1.65 \mathrm{~g}$ & $0.4 \mathrm{~g}$ \\
Iron & $8 \mathrm{mg}$ & $8 \mathrm{mg}$ \\
Inulin & - & $6 \mathrm{~g}$ \\
\hline
\end{tabular}

\subsection{Outcome Measures}

Adult volunteers completed a baseline questionnaire (about themselves and their children). Adult and child participants then consumed the chosen breakfast cereal or no breakfast (if that was usual for the child) for two weeks. Adult participants rated their own and their child or children's wellbeing by completing questionnaires every week (see supplementary material). These questionnaires were used because of their prior use in studies of the effects of breakfast cereal (Smith et al., 2001) and other types of cereal (Smith, 2010, 2018). They also rated their own and their children's alertness levels before and after breakfast at baseline and days 7 and 14 using a visual analogue scale (see supplementary material).

\subsection{Testing Schedule}

The details of the study and how to complete the questionnaires were explained carefully and in full at initial meetings with the families. At these meetings they were given the opportunity to try the available cereals). Adult participants were given the participant information sheet and completed the consent forms and the baseline questionnaire (see supplementary information). At the end of the meeting families were given a 14 day supply (each serving being $30 \mathrm{~g}$ ) of their chosen breakfast cereal (if appropriate) and the two weekly questionnaires (see supplementary information). They were also given a reminder sheet summarising when they should complete 
each part of the study. The weekly questionnaires were completed at home by the adult participants.

\subsection{Statistical Analysis}

Following data collection an anonymised database was created. All names and other identifying details were removed so that no data could be linked back to any individual or to any school. The baseline characteristics of the cereal/no-breakfast groups were compared using ANOVA and Chi-squared analyses. There were no significant gender differences between the breakfast conditions for either adults $(p=0.97)$ or children $(p=0.54)$. The ages of the adults in the groups were also similar $(p=0.18)$, but the children in the no-breakfast group were slightly older than those in the other three conditions $(p=0.01)$. The final database was used in analyses of co-variance. The initial factors in the model were the baseline covariates. Cereal and no-breakfast conditions were then compared. The amount of missing data was small and the accuracy of data input high.

\section{Results}

\subsection{Effects of Breakfast on Wellbeing}

Those in the breakfast cereal conditions had lower scores than the no breakfast group for depression, anxiety, cognitive difficulties, emotional distress, somatic symptoms, fatigue, general health and digestive symptoms (see Table 3; all $p$ values $<0.001$ ). These effects appeared consistent across the different cereals, across both adults and children, and were significant at both week 1 and 2 (after adjusting for baseline scores).

Table 3. Effects of breakfast condition on wellbeing (scores are the adjusted means - high scores = greater anxiety, depression, etc)

\begin{tabular}{lllllll}
\hline & \multicolumn{2}{l}{ No Breakfast } & \multicolumn{2}{l}{ Rice Krispies } & \multicolumn{2}{l}{ Multi-grain } \\
\hline & Adults & Children & Adults & Children & Adults & Children \\
\cline { 2 - 7 } Anxiety & 4.26 & 3.67 & 3.06 & 3.11 & 2.92 & 2.76 \\
Depression & 3.69 & 2.28 & 1.93 & 1.57 & 1.31 & 1.55 \\
Emotional distress & 32.5 & 30.9 & 24.7 & 25.5 & 22.4 & 24.6 \\
Cognitive difficulties & 23.4 & 20.3 & 17.0 & 15.8 & 14.9 & 15.1 \\
Fatigue & 28.1 & 20.3 & 17.1 & 17.6 & 16.8 & 16.8 \\
Somatic symptoms & 23.2 & 19.3 & 18.8 & 17.7 & 17.9 & 17.5 \\
Symptoms & 4.2 & 2.7 & 1.8 & 1.4 & 1.9 & 1.4 \\
Digestive problems & 6.3 & 3.8 & 2.9 & 2.4 & 2.6 & 2.5 \\
\hline
\end{tabular}

\subsection{Breakfast, Inulin and Alertness}

The wellbeing measures showed big differences between the no-breakfast and the cereal conditions but little difference between the Rice Krispie and Multi-grain groups. However, the alertness ratings at day 14 revealed significant differences not only between the cereal conditions and no-breakfast condition, but also between the Rice Krispie and Multi-grain groups. These results are described in Table 4 and it can be seen that the cereal with inulin (the Multi-grain group) was associated with significantly higher alertness scores than the Rice Krispie group. The differences between the cereal conditions were observed for both adults and children.

Table 4. Alertness ratings before and after breakfast on days 7 and 14 (scores are the adjusted means, higher scores $=$ greater alertness)

\begin{tabular}{lcccccc}
\hline \multirow{2}{*}{ Time } & \multicolumn{2}{c}{ No breakfast } & \multicolumn{2}{c}{ Rice Krispies } & \multicolumn{2}{c}{ Multi-grain } \\
\cline { 2 - 7 } & Adult & Child & Adult & Child & Adult & Child \\
\hline Day 7, before breakfast & 400.6 & 382.7 & 460.8 & 461.2 & 448.5 & 475.5 \\
Day 7, after breakfast & 544.4 & 553.4 & 611.4 & 616.2 & 616.7 & 661.7 \\
Day 14, before breakfast & 400.2 & 419.2 & 433.5 & 477.5 & 487.1 & 486.3 \\
Day 14, after breakfast & 560.4 & 598.6 & 628.7 & 642.3 & 651.0 & 678.3 \\
\hline
\end{tabular}

Day 7 before breakfast analysis:

Main effect of breakfast condition: F 2,291 = 8.5 p < 0.001;

No breakfast v Rice Krispies: $\mathrm{p}<0.001 \mathrm{MD}=65.0 \mathrm{se}=19.2$

No Breakfast v Multi-grain: $\mathrm{p}<0.001 \mathrm{MD}=78.0 \mathrm{se}=19.8$

Rice Krispies v Multi-grain: $\mathrm{p}=0.44$

Adult $v$ Child: $p=0.72$. Condition $\times$ Adult $/$ Child: $p=0.53$ 
Day 7 after breakfast analysis:

Main effect of breakfast condition: F 2,291 = 4.77 p < 0.01;

No breakfast $v$ Rice Krispies: $\mathrm{p}=0.23$

No Breakfast v Multi-grain: $\mathrm{p}<0.005 \mathrm{MD}=47.8 \mathrm{se}=20.4$

Rice Krispies v Multi-grain: $\mathrm{p}=0.28$

Adult $v$ Child: $p=0.92$. Condition $x$ Adult/Child: $p=0.15$

Day 14 before breakfast analysis:

Main effect of breakfast condition: F 2,291 = 8.49 p < 0.001;

No breakfast $v$ Rice Krispies: $\mathrm{p}<0.05 \mathrm{MD}=41.6 \mathrm{se}=19.2$

No Breakfast v Multi-grain: $\mathrm{p}<0.001 \mathrm{MD}=85.9 \mathrm{se}=21.1$

Rice Krispies v Multi-grain: $p=0.014 \mathrm{MD}=44.3 \mathrm{se}=18$

Adult v Child: $p=0.52$. Condition $x$ Adult/Child: $p=0.09$

Day 7 after breakfast analysis:

Main effect of breakfast condition: F 2,291 = 4.77 p < 0.01;

No breakfast $v$ Rice Krispies: $p=0.063$

No Breakfast v Multi-grain: $\mathrm{p}<0.001 \mathrm{MD}=54.2 \mathrm{se}=15.0$

Rice Krispies v Multi-grain: $\mathrm{p}<0.05 \mathrm{MD}=28.8 \mathrm{se}=12.1$

Adult $v$ Child: $\mathrm{p}=0.24$. Condition $x$ Adult/Child: $\mathrm{p}=0.78$

\section{Discussion}

\subsection{General Effects of RTEC:}

The results from this study confirm that consumption of breakfast cereal is associated with better wellbeing. However, there was no evidence of significant differences in the effect on wellbeing between the two cereals.

\subsection{Differences between Cereals:}

Inulin has been used to supplement breakfast cereal and this study involved a 14 day intervention and compared effects of no breakfast, Rice Krispies and a Multi-grain cereal fortified with $2 \mathrm{~g}$ inulin. This was part of a programme of research which examined effects of breakfast cereal on adults and children (Smith, 2010b) with a special emphasis on the alerting effects of consuming ready-to-eat breakfast cereals (Smith, 2018). The results from this study confirmed the wide ranging benefits of consuming breakfast. The effects of adding inulin to the cereal were more specific, with alertness increasing only after 14 days of consumption. This is similar to the result found in an earlier wheat bran intervention study (Smith et al., 2001). However, this alerting effect was not found in a similar intervention study with a higher dose of inulin (Smith, 2005). It is possible that the negative effects of a larger dose of inulin counteract longer term prebiotic effects that may occur with smaller doses eaten with carbohydrate.

Smith (2005) put forward two possible mechanisms that could underlie effects of inulin on alertness. The first involves fibre being fermented by gut flora to produce short chain fatty acids. The subsequent use of short-term fatty acids can then provide a major contribution to a person's energy needs. Acetate leads to ATP being generated, and, in addition, short-term fatty acids have been shown to have neuro-active properties (Sampson \& Mazmanian, 2015). The second mechanism is detoxification. Clostridia form neurotoxins and these come from protein metabolism rather than from carbohydrate or fibre. Fibre stimulates bifidobacteria and lactobacilli that do not give rise to toxins. The detoxification that follows ingestion of prebiotics is a slow process and the energising effects of short-term fatty acids would appear to be better able to account for the alerting effects of the inulin seen in the present study.

The present research has a number of limitations. A first limitation of the study was the type of cereal used. The Multi-grain and Rice Krispie conditions had very similar macro-nutrient composition. However, the Multi-grain cereal included flour from other cereals that may have prebiotic effects which means that one cannot definitely attribute differences between the cereals to the supplementation of inulin. Another limitation was the lack of appropriate physiological measures to identify underlying mechanisms. The study of pre-biotic effects has 
largely been based on faecal sampling but in the future it will be important to also use other invasive techniques to investigate changes in the microbiota in the upper gut (Desmedt et al., 2019). In order to examine the gut-brain axis it will be important to use a multi-method approach including metagenomics, metatranscriptonomic and metaproteonomic analysis (Desmedt et al., 2019). Gas or liquid chromatography, in combination with mass spectroscopy, could measure changes of key metabolites. Imaging mass spectroscopy could present a clearer profile of the interaction between the brain and gut microbes.

\section{Acknowledgements}

I would like to thank Marie Thomas for assistance with data collection.

\section{Conflict of interest}

The author declares no conflict of interest.

\section{Funding}

The study was funded by Kellogg's.

\section{References}

Berrill, J. W., Gallacher, J., Hood, K., Green, J. T., Matthews, S. B., Campbell, A. K., \& Smith, A. P. (2013). An observational study of cognitive function in patients with irritable bowel syndrome and inflammatory bowel disease. Neurogastroenterology \& Motility, 25(11), 918-925. https://doi.org/10.1111/nmo.12219

Desmedt, O., Broers, V. J. V., Zamariola, G., Pachikian, B., Delzenne, N., \& Luminet, O. (2019). Effects of prebiotics on affect and cognition: lessons from intervention studies in humans. Nutrition Reviews, 77(2), 81-95. https://doi.org/10.1093/nutrit/nuy052

Gibson, G. R., Beatty, E. R., Wang, X., \& Cummings, J. H. (1995). Selective stimulation of bfidobacteria in the human colon by oligofructose and inulin. Gastroenterology, 108(4), 975-982. https://doi.org/10.1016/0016-5085(95)90192-2

Gibson, G. R., Hutkins, R. W., Sanders, M. E., Prescott, S. L., Reimer, R. A., Salminen, S. J., .. Verbeke, K. (2017). The International Scientific Association for Probiotics and Prebiotics (ISAPP) consensus statement on the definition and scope of prebiotics. Nat Rev Gastroenterol Hepatol, 14(8), 491-502. https://doi.org/10.1038/nrgastro.2017.75

Holm, S. (1979). A simple sequentially rejective multiple test procedure. Scandanavian Journal of Statistics, 6(2), 65-70.

Kennedy, P., Clarke, G., O`Neill, A., Groeger, J., Quigley, E., Shanahan, F., Cryan, J., \& Dinan, T. (2014). Cognitive performance in irritable bowel syndrome: evidence of a stress-related impairment in visuospatial memory. Psychological Medicine, 44(7), 1553-1566. https://doi.org/10.1017/s0033291713002171

Roberfroid, M. B. (2007). Inulin-type fructans: Functional food ingredients. The Journal of Nutrition, 137(11), 24935-25025. https://doi.org/10.1093/jn/137.11.2493s

Sampson, T. R., \& Mazmanian, S. K. (2015). Control of brain development, function, and behavior by the microbiome. Cell Host \& Microbe, 17(5), 565-576. https://doi.org/10.1016/j.chom.2015.04.011

Smith, A. P. (2005). The concept of well-being: relevance to nutritional research. British Journal of Nutrition, 93(S1), S1-S5. https://doi.org/10.1079/bjn20041351

Smith, A. P. (2010a). Breakfast cereal, fibre, digestive problems and well-being. Current Topics in Nutraceutical Resesearch, 8(2/3), 117-126.

Smith, A. P. (2010b). An investigation of the effects of breakfast cereals on alertness, cognitive function and other aspects of the well-being of children. Nutritional Neuroscience, 13(5), 230-236. https://doi.org/10.1179/147683010x12611460764642

Smith, A. P. (2011). Breakfast cereal, digestive problems and well-being. Stress and Health, 27(5), 388-394. https://doi.org/10.1002/smi.1390

Smith, A. P. (2018). Cornflakes, well-being and cognition. Current Topics in Nutraceutical Resesearch, 16(3), 207-218.

Smith, A. P. (2019). Effects of oligofructose-enriched inulin on subjective wellbeing, mood and cognitive performance. Journal of Food Research, 8(5), 33-40. https://doi.org/10.5539/jfr.v8n5p33

Smith, A. P., Bazzoni, C., Beale, J., Elliott-Smith, J., \& Tiley, M. (2001). High fibre breakfast cereals reduce 
fatigue. Appetite, 37(3), 249-250. https://doi.org/10.1006/appe.2001.0428

Smith, A. P., Johal, S. S., Wadsworth, E., Davey Smith, G., \& Peters, T. (2000). The Scale of Occupational Stress: the Bristol Stress and Health at Work Study. Sudbury: HSE Books.

Smith, A. P., Sutherland, D., \& Hewlett, P. (2015). An investigation of the acute effects of oligofructose-enriched inulin on subjective wellbeing, mood and objective measures of cognitive performance. Nutrients, 7(11), 8887-8896. https://doi.org/10.3390/nu7115441

\section{Supplementary Material}

\section{ADULT 1}

Below is a list of problems which may or may not apply to you. For each problem, please say to what extent you have experienced this during the PAST 7 days (including today). Do not think for too long before answering but give your immediate reaction. Please be careful not to miss out any of the items. Remember, we are talking about the past week and not in general. Give your answer by circling any number from 1 to 7 to the right of the item, where;

\section{$1=$ not at all, $4=$ moderately and $7=$ extremely}

\begin{tabular}{|c|c|c|c|c|c|c|c|c|}
\hline & & not at all & & & moderately & & & extremely \\
\hline 1 & Feeling physically tired even when taking things easy & 1 & 2 & 3 & 4 & 5 & 6 & 7 \\
\hline 2 & Your limbs feeling heavy & 1 & 2 & 3 & 4 & 5 & 6 & 7 \\
\hline 3 & Getting easily upset by things & 1 & 2 & 3 & 4 & 5 & 6 & 7 \\
\hline 4 & Difficulty concentrating & 1 & 2 & 3 & 4 & 5 & 6 & 7 \\
\hline 5 & Stomach pain & 1 & 2 & 3 & 4 & 5 & 6 & 7 \\
\hline 6 & Not having the physical energy to do anything & 1 & 2 & 3 & 4 & 5 & 6 & 7 \\
\hline 7 & Difficulty standing for long & 1 & 2 & 3 & 4 & 5 & 6 & 7 \\
\hline 8 & Losing your temper easily & 1 & 2 & 3 & 4 & 5 & 6 & 7 \\
\hline 9 & Difficulty remembering things & 1 & 2 & 3 & 4 & 5 & 6 & 7 \\
\hline 10 & Muscles feel weak even after resting & 1 & 2 & 3 & 4 & 5 & 6 & 7 \\
\hline 11 & Feeling depressed & 1 & 2 & 3 & 4 & 5 & 6 & 7 \\
\hline 12 & Muscles tender to the touch & 1 & 2 & 3 & 4 & 5 & 6 & 7 \\
\hline 13 & Slowness of thought & 1 & 2 & 3 & 4 & 5 & 6 & 7 \\
\hline 14 & Tremor or twitching & 1 & 2 & 3 & 4 & 5 & 6 & 7 \\
\hline 15 & The slightest exercise making you physically tired & 1 & 2 & 3 & 4 & 5 & 6 & 7 \\
\hline 16 & Being irritable & 1 & 2 & 3 & 4 & 5 & 6 & 7 \\
\hline 17 & Difficulty reasoning things out & 1 & 2 & 3 & 4 & 5 & 6 & 7 \\
\hline 18 & Burning, tingling or crawling sensations & 1 & 2 & 3 & 4 & 5 & 6 & 7 \\
\hline 19 & Numbness in some part of your body & 1 & 2 & 3 & 4 & 5 & 6 & 7 \\
\hline 20 & Back pain & 1 & 2 & 3 & 4 & 5 & 6 & 7 \\
\hline 21 & Feeling anxious & 1 & 2 & 3 & 4 & 5 & 6 & 7 \\
\hline 22 & A feeling of confusion ('mental fog') & 1 & 2 & 3 & 4 & 5 & 6 & 7 \\
\hline 23 & Bouts of sweating (day or night) & 1 & 2 & 3 & 4 & 5 & 6 & 7 \\
\hline 24 & Feeling physically drained & 1 & 2 & 3 & 4 & 5 & 6 & 7 \\
\hline 25 & Dizziness or giddiness & 1 & 2 & 3 & 4 & 5 & 6 & 7 \\
\hline 26 & Absent-mindedness & 1 & 2 & 3 & 4 & 5 & 6 & 7 \\
\hline 27 & Worrying about things that do not matter & 1 & 2 & 3 & 4 & 5 & 6 & 7 \\
\hline 28 & Feeling physically tired even after a good night's sleep & 1 & 2 & 3 & 4 & 5 & 6 & 7 \\
\hline 29 & Difficulty understanding; e.g. what someone was saying to you & 1 & 2 & 3 & 4 & 5 & 6 & 7 \\
\hline 30 & Feeling pessimistic about the future & 1 & 2 & 3 & 4 & 5 & 6 & 7 \\
\hline 31 & Cold hands or feet & 1 & 2 & 3 & 4 & 5 & 6 & 7 \\
\hline 32 & $\begin{array}{l}\text { Having to stop doing something, that was easy in } \\
\text { itself, because it made you tired }\end{array}$ & 1 & 2 & 3 & 4 & 5 & 6 & 7 \\
\hline 33 & Muscles feeling weak after slight exercise & 1 & 2 & 3 & 4 & 5 & 6 & 7 \\
\hline 34 & Difficulty following things; e.g. a simple plot on TV & 1 & 2 & 3 & 4 & 5 & 6 & 7 \\
\hline 35 & Hot or cold spells & 1 & 2 & 3 & 4 & 5 & 6 & 7 \\
\hline
\end{tabular}




\begin{tabular}{|c|c|c|c|c|c|c|c|c|}
\hline & & not at all & & & moderately & & & extremely \\
\hline 36 & Feeling tense & 1 & 2 & 3 & 4 & 5 & 6 & 7 \\
\hline 37 & Feeling faint & 1 & 2 & 3 & 4 & 5 & 6 & 7 \\
\hline 38 & Difficulty finding the right word & 1 & 2 & 3 & 4 & 5 & 6 & 7 \\
\hline 39 & Feeling chilled or shivery & 1 & 2 & 3 & 4 & 5 & 6 & 7 \\
\hline 40 & Tearfulness & 1 & 2 & 3 & 4 & 5 & 6 & 7 \\
\hline 41 & Irregular or rapid heartbeats & 1 & 2 & 3 & 4 & 5 & 6 & 7 \\
\hline 42 & Feeling worthless & 1 & 2 & 3 & 4 & 5 & 6 & 7 \\
\hline 43 & Forgetting what you were trying to say & 1 & 2 & 3 & 4 & 5 & 6 & 7 \\
\hline 44 & Being easily angered when things went wrong & 1 & 2 & 3 & 4 & 5 & 6 & 7 \\
\hline 45 & Feeling mentally tired even after a good night's sleep & 1 & 2 & 3 & 4 & 5 & 6 & 7 \\
\hline 46 & Diarrhoea or constipation & 1 & 2 & 3 & 4 & 5 & 6 & 7 \\
\hline 47 & Feeling nervous & 1 & 2 & 3 & 4 & 5 & 6 & 7 \\
\hline 48 & Feeling sad & 1 & 2 & 3 & 4 & 5 & 6 & 7 \\
\hline 49 & The slightest effort making you mentally tired & 1 & 2 & 3 & 4 & 5 & 6 & 7 \\
\hline 50 & Feeling like you had a temperature & 1 & 2 & 3 & 4 & 5 & 6 & 7 \\
\hline 51 & Other people annoying you & 1 & 2 & 3 & 4 & 5 & 6 & 7 \\
\hline 52 & A sore throat & 1 & 2 & 3 & 4 & 5 & 6 & 7 \\
\hline 53 & Feelings of resentment & 1 & 2 & 3 & 4 & 5 & 6 & 7 \\
\hline 54 & Being slow to react & 1 & 2 & 3 & 4 & 5 & 6 & 7 \\
\hline
\end{tabular}

Below is a list of words that describe feelings people have. We would like to know to what degree each word describes how you have been feeling during the past 7 days. Please circle the number which you feel most applies to you.

1. How attentive have you felt?

$0=$ Not at all 1= A little 2= Moderately 3= Quite a bit $4=$ Extremely

2. How distressed have you felt?

$0=$ Not at all 1= A little 2= Moderately 3= Quite a bit $4=$ Extremely

3. How proud?

0= Not at all 1= A little $\quad 2=$ Moderately $3=$ Quite a bit $\quad 4=$ Extremely

4. How nervous?

$0=$ Not at all 1= A little 2= Moderately 3= Quite a bit $4=$ Extremely

5. How sad have you felt?

$0=$ Not at all 1= A little 2= Moderately 3= Quite a bit $4=$ Extremely

6. How active?

$0=$ Not at all 1= A little 2= Moderately $3=$ Quite a bit $\quad 4=$ Extremely

7. How friendly?

0= Not at all 1= A little 2= Moderately 3= Quite a bit $4=$ Extremely

8. How angry have you felt?

$0=$ Not at all $\quad 1=$ A little $\quad 2=$ Moderately $\quad 3=$ Quite a bit $\quad 4=$ Extremely

9. How dissatisfied with yourself?

0= Not at all 1= A little 2= Moderately 3= Quite a bit $4=$ Extremely

10. How tired?

$0=$ Not at all $\quad 1=$ A little $\quad 2=$ Moderately $\quad 3=$ Quite a bit $\quad 4=$ Extremely

11. How healthy have you felt?

$0=$ Not at all 1= A little 2= Moderately $3=$ Quite a bit $4=$ Extremely

12. How calm? 
0= Not at all 1= A little 2= Moderately 3= Quite a bit $4=$ Extremely

13. How guilty have you felt?

$0=$ Not at all 1= A little 2= Moderately $3=$ Quite a bit $\quad 4=$ Extremely

14. How scared have you felt?

$0=$ Not at all 1= A little 2= Moderately $3=$ Quite a bit $\quad 4=$ Extremely

15. How happy?

$0=$ Not at all 1= A little 2= Moderately 3= Quite a bit 4= Extremely

16. How emotionally strong have you felt?

$0=$ Not at all 1= A little 2= Moderately 3= Quite a bit 4= Extremely

17. How confident have you felt?

$0=$ Not at all 1= A little $\quad 2=$ Moderately $3=$ Quite a bit $\quad 4=$ Extremely

18. How angry at yourself?

0= Not at all 1= A little 2= Moderately 3= Quite a bit $4=$ Extremely

19. How upset?

$0=$ Not at all 1= A little 2= Moderately $3=$ Quite a bit $\quad 4=$ Extremely

20. How alert have you felt?

$0=$ Not at all 1= A little $\quad 2=$ Moderately $\quad 3=$ Quite a bit $\quad 4=$ Extremely

21. How irritated?

$0=$ Not at all 1= A little 2= Moderately $3=$ Quite a bit $\quad 4=$ Extremely

22. How depressed?

$0=$ Not at all 1= A little 2= Moderately 3= Quite a bit $\quad 4=$ Extremely

23. How enthusiastic have you felt?

$0=$ Not at all 1= A little 2= Moderately 3= Quite a bit $4=$ Extremely

24. How sleepy?

0= Not at all 1= A little 2= Moderately 3= Quite a bit $4=$ Extremely

25. How warm hearted have you felt?

0= Not at all 1= A little 2= Moderately 3= Quite a bit $4=$ Extremely

26. How excited have you felt?

$0=$ Not at all 1= A little 2= Moderately $3=$ Quite a bit $\quad 4=$ Extremely

27. How hostile?

$0=$ Not at all $1=$ A little $\quad 2=$ Moderately $3=$ Quite a bit $\quad 4=$ Extremely

28. How shaky?

$0=$ Not at all $\quad 1=$ A little $\quad 2=$ Moderately $\quad 3=$ Quite a bit $\quad 4=$ Extremely

29. How determined have you felt?

$0=$ Not at all 1= A little $\quad 2=$ Moderately $\quad 3=$ Quite a bit $\quad 4=$ Extremely

30. How content?

$0=$ Not at all 1= A little $\quad 2=$ Moderately $\quad 3=$ Quite a bit $\quad 4=$ Extremely 


\section{SYMPTOM CHECK-LIST}

Please tick the boxes which best describe any symptoms over the last 7 days:

\begin{tabular}{|l|c|}
\hline 1. Physical weakness & $\square$ \\
\hline 2. Excessive fatigue & $\square$ \\
\hline 3. Legs feeling heavy & $\square$ \\
\hline 4. Muscle pain in back, arms or legs & $\square$ \\
\hline 5. Pain in chest & $\square$ \\
\hline 6. Painful joints & $\square$ \\
\hline 7. Nausea & $\square$ \\
\hline 8. Indigestion & $\square$ \\
\hline 9. Bloated stomach & $\square$ \\
\hline 10. Wind & $\square$ \\
\hline 11. Sore throat & $\square$ \\
\hline 12. Headache & $\square$ \\
\hline 13. Earache & $\square$ \\
\hline 14. Sore eyes & $\square$ \\
\hline 15. Sensitive to noise & $\square$ \\
\hline 16. Sensitive to light & $\square$ \\
\hline 17. Feeling hot/cold & $\square$ \\
\hline 18. Sweating & $\square$ \\
\hline 19. Shivering & $\square$ \\
\hline 20. Swollen glands & $\square$ \\
\hline 21. Racing heart & $\square$ \\
\hline 22. Insomnia & $\square$ \\
\hline 23. Depression & $\square$ \\
\hline 24. Anxiety/Panic feelings & $\square$ \\
\hline 25. Loss of concentration & $\square$ \\
\hline 26. Loss of memory & $\square$ \\
\hline
\end{tabular}

Please complete the following questions about your nightly sleeping habits over the past 7 days.

1. How many hours, on average, did you sleep at night? hours.

2. How often did you feel rested from your night's sleep?

$$
0=\text { never } \quad 1=\text { almost never } \quad 2=\text { =sometimes } \quad 3 \text { =fairly often } \quad 4=\text { =very often }
$$

3. How often did you have difficulty falling asleep at night?

$$
0=\text { never } \quad 1=\text { almost never } \quad 2 \text { =sometimes } \quad 3 \text { =fairly often } \quad 4=\text { =very often }
$$

4. How often did you awaken earlier than your usual waking time? 


$$
0=\text { never } \quad 1=\text { almost never } \quad 2=\text { sometimes } \quad 3 \text { =fairly often } \quad 4=\text { very often }
$$

This questionnaire is designed to help describe how you have felt over the last 7 days. Read each item and then circle the number that comes closest to how you have been feeling in the past week. Try to give your first reaction. This will probably be more accurate than spending a lot of time thinking about an answer.

1. I felt tense or wound up

Most of the time

$$
\left[\begin{array}{ll}
3 & ]
\end{array}\right.
$$

A lot of the time

Time to time, occasionally

$$
\text { [ } 1 \text { ] }
$$

Not at all

[ $\begin{array}{ll}0 & ]\end{array}$

2. I still enjoyed the things I used to enjoy

Definitely as much

$$
\left[\begin{array}{ll}
0 & ]
\end{array}\right.
$$

Not quite so much

Only a little

Hardly at all

3. I got a sort of frightened feeling as if something awful is about to happen

Very definitely and quite badly

$$
\text { [ } 3 \text { ] ] }
$$

Yes, but not too badly

A little, but it doesn't worry me

Not at all

$$
\text { [ } 0 \text { ] }
$$

4. I could laugh and see the funny side of things

As much as I always could $\left[\begin{array}{ll}0 & ]\end{array}\right.$

Not quite as much now

$$
\left[\begin{array}{ll}
1 & ]
\end{array}\right.
$$

Definitely not so much now

$$
\text { [ } 2 \text { ] }
$$

Not at all

\begin{tabular}{|c|c|}
\hline Not at all & {$[3$} \\
\hline Not often & {$[2$} \\
\hline Sometimes & \\
\hline Most of the time & \\
\hline
\end{tabular}
[ 3 ]

5. Worrying thoughts went through my mind

\begin{tabular}{|c|c|}
\hline Definitely & {$[0$} \\
\hline Usually & {$[1$} \\
\hline Not often & {$[2$} \\
\hline Not at all & {$[3$} \\
\hline
\end{tabular}

A great deal of the time [ 3 ]

A lot of the time [ [ ]

From time to time but not too often [ 1 ]

Only occasionally [ [ $\begin{array}{ll}0 & ]\end{array}$

6. I felt cheerful

7. I could sit at ease and feel relaxed

8. I felt as if I was slowed down

Nearly all the time

Very often

Sometimes 
Not at all [ $\begin{array}{ll}0 & ]\end{array}$

9. I got a sort of frightened feeling like "butterflies" in the stomach

Not at all

[ 0 l ]

Occasionally

[ 1 ]

Quite often

[ 2 ]

Very often

[ 3 ]

10. I have lost interest in my appearance

Definitely [ 3 ]

I don't take as much care as I should [ 2 ]

I may not take quite as much care [ 1 ]

I take just as much care as ever [ 0 ]

11. I felt restless as if I have to be on the move

Very much indeed

[ 3 ]

Quite a lot

[ 2 ]

Not very much

[ 1 ]

Not at all [ 0 ] ]

12. I looked forward with enjoyment to things

As much as I ever did

Rather less than I used to

[ 1 ]

Definitely less than I used to

[ 2 ]

Hardly at all

13. I got sudden feelings of panic

Very often indeed

Quite often

Not very often

Not at all [ 0 ] ]

14. I could enjoy a good book or radio or TV programme

Often

$\left[\begin{array}{ll}0 & ]\end{array}\right.$

Sometimes

Not often

[ 2 ]

Very seldom

Using this scale, we'd like to ask you about some physical symptoms that people often experience. For each symptom we would like you to indicate how much that problem has bothered or distressed you during the past seven days, including today. For each, we'd like you to answer by circling 'not at all', 'a little bit', 'moderately', 'quite a bit' or 'extremely'.

In the past seven days how often were you bothered by :

\section{Constipation}

$0=$ not at all

$1=a$ little bit

$$
\begin{aligned}
& 2=\text { moderately } \\
& 3=\text { quite a bit }
\end{aligned}
$$$$
4=\text { extremely }
$$

2. Diarrhoea

$0=$ not at all

$1=\mathrm{a}$ little bit

$$
2=\text { moderately }
$$$$
4=\text { extremely }
$$

3 = quite $a$ bit 
3. Indigestion

$0=$ not at all

$1=$ a little bit

$$
\begin{aligned}
& 2=\text { moderately } \\
& 3=\text { quite a bit }
\end{aligned}
$$

$$
4=\text { extremely }
$$

4. Nausea and/or vomiting

$0=$ not at all

$2=$ moderately

4 = extremely

$1=$ a little bit

$3=$ quite a bit

5. Stomach pains (e.g. cramps)

$0=$ not at all

$2=$ moderately

$4=$ extremely

$1=$ a little bit

$3=$ quite a bit

6. Wind

$0=$ not at all

$1=$ a little bit

$2=$ moderately

$4=$ extremely

3 = quite a bit

7. Poor appetite

$0=$ not at all

$2=$ moderately

$4=$ extremely

$1=\mathrm{a}$ little bit

$3=$ quite $a$ bit

8. Weight loss/feeling slimmer

$0=$ not at all

$1=a$ little bit

$2=$ moderately

$4=$ extremely

$3=$ quite a bit

Pain in Bowels

$0=$ not at all

$2=$ moderately

4 = extremely

$1=$ a little bit

3 = quite a bit

Incomplete evacuation of bowels

$0=$ not at all

$2=$ moderately

$4=$ extremely

$1=$ a little bit

3 = quite a bit

11. Bloatedness

$0=$ not at all

$1=$ a little bit

$2=$ moderately

3 = quite a bit

$4=$ extremely

Over the last week please indicate how many bowls of breakfast cereal you consumed each morning for breakfast (please round up to the nearest half bowl). Also would you indicate how much you enjoyed the cereal on a scale of 0 to 10 where $0=$ not at all and $10=$ very much indeed. If you were not supplied with breakfast cereal please put 0 bowls consumed for each day.

\begin{tabular}{|l|l|l|}
\hline & Number of bowls consumed each day & How much did you enjoy it (0-10)? \\
\hline Monday & & \\
\hline Tuesday & & \\
\hline Wednesday & & \\
\hline Thursday & & \\
\hline Friday & & \\
\hline Saturday & & \\
\hline Sunday & & \\
\hline
\end{tabular}

Thank you for completing this section of the booklet.

Now please make sure that a separate section is completed for each member of your family taking part in the study.

This section of the booklet is for the first child who is taking part in the study. It should be completed on DAY 7 
by an adult on behalf of the child. If more than one adult from your family is involved in the study, either or both of them can complete this section. It should take up to an hour to fill in.

The questions in this section are worded in exactly the same way as they were in the section about you. This may make one or two of them seem unusual to ask about a child. We have done it like this so that we can compare the information with our previous work on adults.

It is important that you complete the questions on behalf of your child. There is no need to directly ask him or her any of the questions. We are simply trying to get an overall impression of your opinion about him or her.

To make things easier, each person's section is colour coded: $1^{\text {st }}$ adult $=$ green $; 2^{\text {nd }}$ adult $=$ yellow; oldest child $=$ blue; $2^{\text {nd }}$ child $=$ purple; $3^{\text {rd }}$ child $=$ pink; $4^{\text {th }}$ child $=$ orange; $5^{\text {th }}$ child $=$ cream. It is very important for us that you stick to these colours for each person for ALL of the study!

This questionnaire starts with some questions about how alert each person is feeling. As we explained when we met you, you need to complete these questions on DAY 1 of the study, BEFORE and then again AFTER each person has breakfast. If you have not been supplied with breakfast cereal please complete these questions soon after each person gets up and again about an hour later.

The questions about alertness may take about 30 minutes to complete altogether.

To make things easier, each person's sections are colour coded as before: $1^{\text {st }}$ adult $=$ green; $2^{\text {nd }}$ adult $=$ yellow; oldest child $=$ blue; $2^{\text {nd }}$ child $=$ purple; $3^{\text {rd }}=$ pink; $4^{\text {th }}$ child $=$ orange; $5^{\text {th }}$ child $=$ cream. It is very important for us that you stick to these colours for each person for all of the study!

\begin{tabular}{|c|c|c|}
\hline \multicolumn{3}{|c|}{ ALERTNESS RATING } \\
\hline \multicolumn{2}{|c|}{ DAY 1 BEFORE BREAKFAST } & ADULT 1 \\
\hline \multicolumn{3}{|c|}{$\begin{array}{l}\text { On each of the following lines please draw a cross between the two extremes which } \\
\text { best represents how you are feeling now. }\end{array}$} \\
\hline Drowsy & 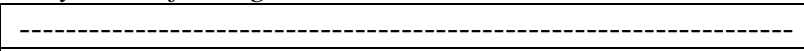 & Alert \\
\hline Strong & 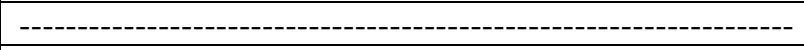 & Feeble \\
\hline Muzzy & 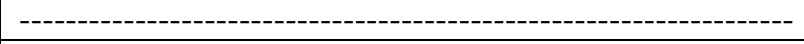 & Clear-headed \\
\hline Co-ordi & - & Clumsy \\
\hline Letha & - & Energetic \\
\hline Mentally-slow & ---- & Quic \\
\hline Attentive & 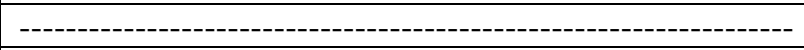 & Dre \\
\hline Incom & 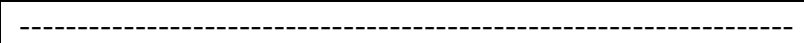 & Pro \\
\hline Not at all tired & 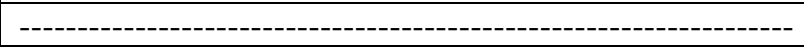 & ly tired \\
\hline \multicolumn{2}{|c|}{ DAY 1 BEFORE BREAKFAST } & ADULT 2 \\
\hline \multicolumn{3}{|c|}{$\begin{array}{l}\text { On each of the following lines please draw a cross between the two extremes which } \\
\text { best represents how you are feeling now. }\end{array}$} \\
\hline Drowsy & ---------- & Alert \\
\hline Strong & 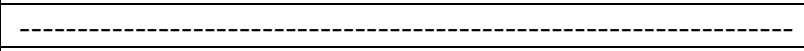 & Feeble \\
\hline Muzzy & 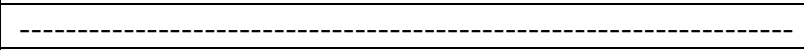 & Clear-headed \\
\hline Co-ordinated & 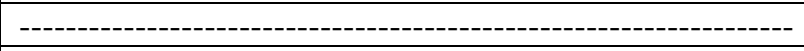 & Clumsy \\
\hline Lethargic & | & Energetic \\
\hline Mentally-slow & 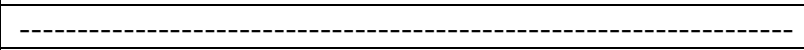 & Quick-witted \\
\hline Attentive & 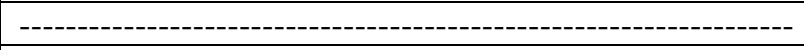 & Dreamy \\
\hline Incompetent & 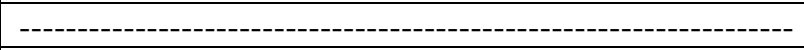 & Proficient \\
\hline Not at all tired & 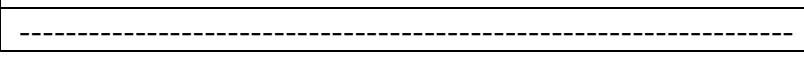 & Extremely tired \\
\hline
\end{tabular}

\begin{tabular}{|c|c|c|}
\hline \multicolumn{3}{|c|}{ ALERTNESS RATING } \\
\hline \multicolumn{2}{|c|}{ DAY 1 BEFORE BREAKFAST } & CHILD 1 \\
\hline \multicolumn{2}{|c|}{ RATINGS COMPLETED BY (please circle) } & ADULT 1 / ADULT 2 \\
\hline \multicolumn{3}{|c|}{$\begin{array}{l}\text { On each of the following lines please draw a cross between the two extremes which } \\
\text { best represents how your child is feeling now. }\end{array}$} \\
\hline Drowsy & - & Alert \\
\hline Strong & 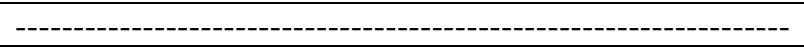 & Feeble \\
\hline Muzzy & 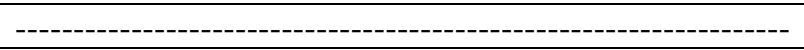 & Clear-headed \\
\hline
\end{tabular}




\begin{tabular}{|c|c|c|}
\hline Co-ordinated & 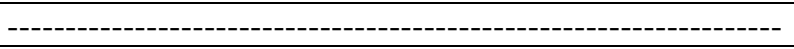 & Clumsy \\
\hline Lethargic & 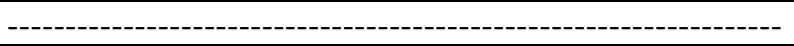 & Energetic \\
\hline Mentally-slow & -------------------------------------------------------------------------------- & Quick-witted \\
\hline Attentive & 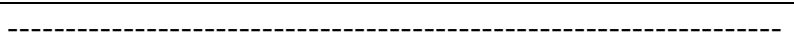 & Dreamy \\
\hline Incompetent & 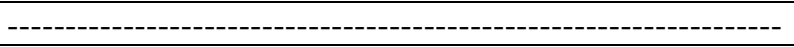 & Proficient \\
\hline \multicolumn{2}{|c|}{ DAY 1 BEFORE BREAKFAST } & CHILD 2 \\
\hline \multicolumn{2}{|c|}{ RATINGS COMPLETED BY (please circle) } & ADULT 1 / ADULT 2 \\
\hline \multicolumn{3}{|c|}{$\begin{array}{l}\text { On each of the following lines please draw a cross between the two extremes which } \\
\text { best represents how your child is feeling now. }\end{array}$} \\
\hline Drowsy & 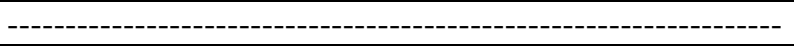 & Alert \\
\hline Strong & 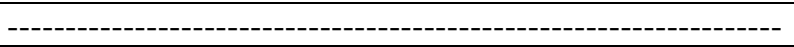 & Feeble \\
\hline Muzzy & -------------------------------------------------------------------------------- & Clear-headed \\
\hline Co-ordinated & 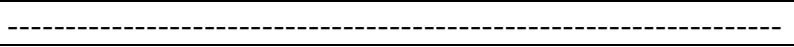 & Clumsy \\
\hline Lethargic & ------------------------------------------------------------------------ & Energetic \\
\hline Mentally-slow & 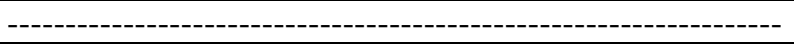 & Quick-witted \\
\hline Attentive & 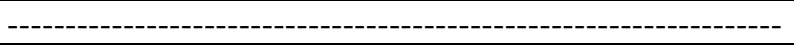 & Dreamy \\
\hline Incompetent & 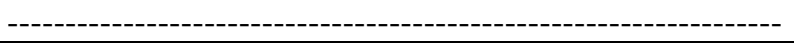 & Proficient \\
\hline \multicolumn{3}{|c|}{ ALERTNESS RATING } \\
\hline \multicolumn{2}{|c|}{ DAY 1 BEFORE BREAKFAST } & CHILD 3 \\
\hline \multicolumn{2}{|c|}{ RATINGS COMPLETED BY (please circle) } & ADULT 1 / ADULT 2 \\
\hline \multicolumn{3}{|c|}{$\begin{array}{l}\text { On each of the following lines please draw a cross between the two extremes which } \\
\text { best represents how your child is feeling now. }\end{array}$} \\
\hline Drowsy & --------------------------------------------------------------------------- & Alert \\
\hline Strong & 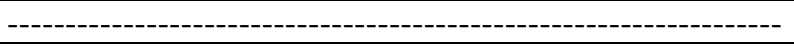 & Feeble \\
\hline Muzzy & 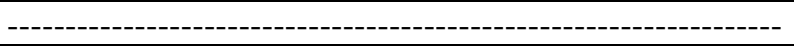 & Clear-headed \\
\hline Co-ordinated & |----------------------------------------------------------------------- & Clumsy \\
\hline Lethargic & ------------------------------------------------------------------------- & Energetic \\
\hline Mentally-slow & 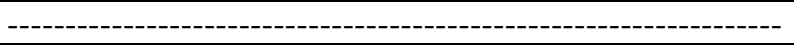 & Quick-witted \\
\hline Attentive & 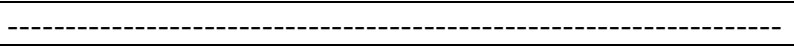 & Dreamy \\
\hline Incompetent & 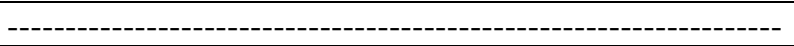 & Proficient \\
\hline \multicolumn{2}{|c|}{ DAY 1 BEFORE BREAKFAST } & CHILD 4 \\
\hline \multicolumn{2}{|c|}{ RATINGS COMPLETEDBY (please circle) } & ADULT 1 / ADULT 2 \\
\hline \multicolumn{3}{|c|}{$\begin{array}{l}\text { On each of the following lines please draw a cross between the two extremes which } \\
\text { best represents how your child is feeling now. }\end{array}$} \\
\hline Drowsy & ------------------------------------------------------------------------------- & Alert \\
\hline Strong & 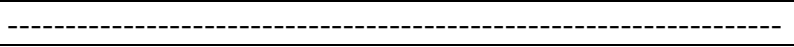 & Feeble \\
\hline Muzzy & $\begin{array}{l}\text {--------------------------------------------------------------------- } \\
\end{array}$ & Clear-headed \\
\hline Co-ordinated & ------------------------------------------------------------------------- & Clumsy \\
\hline Lethargic & 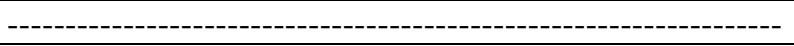 & Energetic \\
\hline Mentally-slow & |--------------------------------------------------------------------- & Quick-witted \\
\hline Attentive & 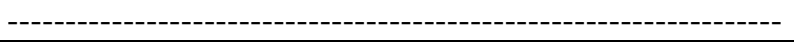 & Dreamy \\
\hline Incompetent & 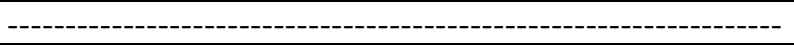 & Proficient \\
\hline
\end{tabular}

\begin{tabular}{|c|c|c|}
\hline \multicolumn{3}{|c|}{ ALERTNESS RATING } \\
\hline \multicolumn{2}{|c|}{ DAY 1 BEFORE BREAKFAST } & CHILD 5 \\
\hline \multicolumn{2}{|c|}{ RATINGS COMPLETED BY (please circle) } & ADULT 1 / ADULT 2 \\
\hline \multicolumn{3}{|c|}{$\begin{array}{l}\text { On each of the following lines please draw a cross between the two extremes which } \\
\text { best represents how your child is feeling now. }\end{array}$} \\
\hline Drowsy & -------------------------------------------------------------------------------- & Alert \\
\hline Strong & 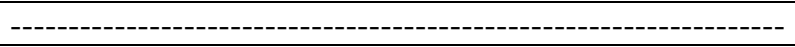 & Feeble \\
\hline Muzzy & 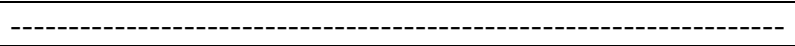 & Clear-headed \\
\hline
\end{tabular}




\begin{tabular}{|c|c|c|}
\hline Co-ordinated & 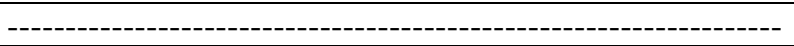 & Clumsy \\
\hline Lethargic & 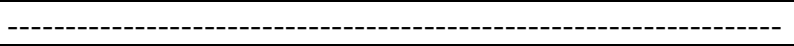 & Energetic \\
\hline Mentally-slow & 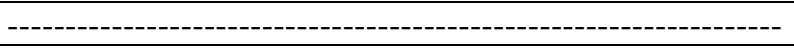 & Quick-witted \\
\hline Attentive & 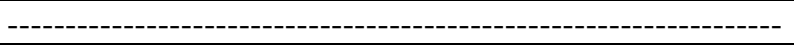 & Dreamy \\
\hline Incompetent & 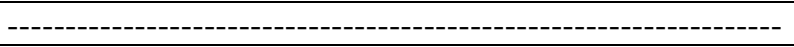 & Proficient \\
\hline
\end{tabular}

\begin{tabular}{|c|c|c|}
\hline \multicolumn{3}{|c|}{ ALERTNESS RATING } \\
\hline \multicolumn{2}{|c|}{ DAY 1 AFTER BREAKFAST } & ADULT 1 \\
\hline \multicolumn{3}{|c|}{$\begin{array}{l}\text { On each of the following lines please draw a cross between the two extremes which } \\
\text { best represents how you are feeling now. }\end{array}$} \\
\hline Drowsy & ---------------------------------------- & Alert \\
\hline Strong & 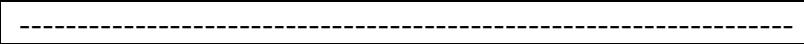 & Feeble \\
\hline Muzzy & 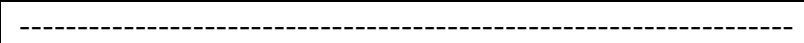 & Clear-headed \\
\hline Co-ordinated & |-1-------------------------------------------------------------------------- & Clumsy \\
\hline Lethargic & |- & Ene \\
\hline Mentally-slow & \begin{tabular}{|l} 
\\
\end{tabular} & Qui \\
\hline Attentive & | & Dre \\
\hline Incon & 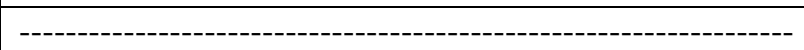 & $\operatorname{Pr}$ \\
\hline Not at all tired & |-------------------------------------------------------------------------- & ly tired \\
\hline \multicolumn{2}{|c|}{ DAY 1 AFTER BREAKFAST } & ADULT 2 \\
\hline \multicolumn{3}{|c|}{$\begin{array}{l}\text { On each of the following lines please draw a cross between the two extremes which } \\
\text { best represents how you are feeling now. }\end{array}$} \\
\hline Drowsy & \begin{tabular}{|l} 
\\
\end{tabular} & Alert \\
\hline Strong & | & Feeble \\
\hline Muzzy & 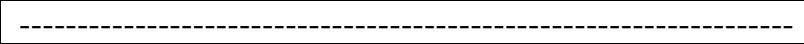 & Clear-headed \\
\hline Co-ordinated & 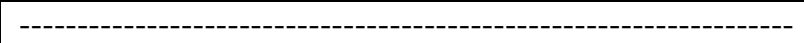 & Clumsy \\
\hline Lethargic & 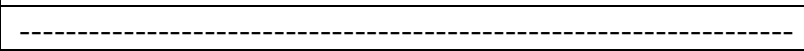 & Energetic \\
\hline Mentally-slow & \begin{tabular}{|l} 
\\
\end{tabular} & Quick-witted \\
\hline Attentive & 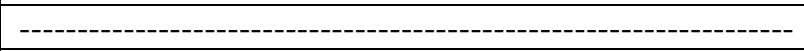 & Dreamy \\
\hline Incompetent & 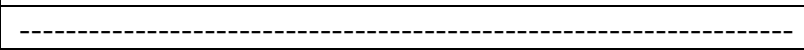 & Proficient \\
\hline Not at all tired & |----------------------------------------------------------------------------- & Extremely tired \\
\hline
\end{tabular}

\begin{tabular}{|c|c|c|}
\hline \multicolumn{3}{|c|}{ ALERTNESS RATING } \\
\hline \multicolumn{2}{|c|}{ DAY 1 AFTER BREAKFAST } & CHILD 1 \\
\hline \multicolumn{2}{|c|}{ RATINGS COMPLETED BY (please circle) } & ADULT 1 / ADULT 2 \\
\hline \multicolumn{3}{|c|}{$\begin{array}{l}\text { On each of the following lines please draw a cross between the two extremes which } \\
\text { best represents how your child is feeling now. }\end{array}$} \\
\hline Drowsy & 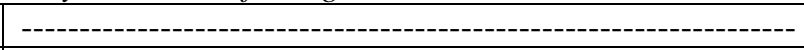 & Alert \\
\hline Strong & 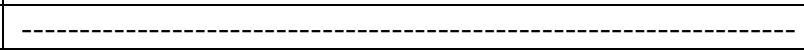 & Feeble \\
\hline Muzzy & \begin{tabular}{|l} 
\\
\end{tabular} & Clear-headed \\
\hline Co-ordinated & |- & Clumsy \\
\hline Lethargic & 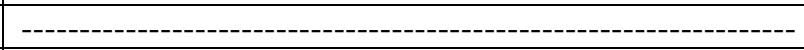 & Energetic \\
\hline Mentally-slow & \begin{tabular}{|l} 
\\
\end{tabular} & Quick-witted \\
\hline Attentive & 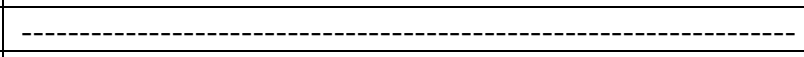 & Dreamy \\
\hline Incompetent & |---------------------------------------------------------------------------- & Proficient \\
\hline \multicolumn{2}{|c|}{ DAY 1 AFTER BREAKFAST } & CHILD 2 \\
\hline RATINGS CO & MPLETED BY (please circle) & ADULT 1 / ADULT 2 \\
\hline \multicolumn{3}{|c|}{$\begin{array}{l}\text { On each of the following lines please draw a cross between the two extremes which } \\
\text { best represents how your child is feeling now. }\end{array}$} \\
\hline Drowsy & \begin{tabular}{|l} 
\\
\end{tabular} & Alert \\
\hline Strong & 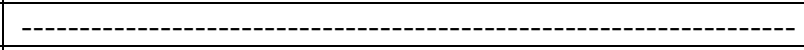 & Feeble \\
\hline Muzzy & -.--... & Clear-headed \\
\hline
\end{tabular}




\begin{tabular}{|c|c|c|}
\hline Co-ordinated & 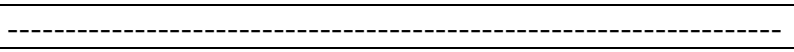 & Clumsy \\
\hline Lethargic & 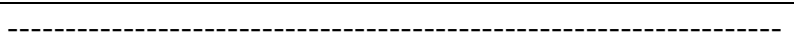 & Energetic \\
\hline Mentally-slow & 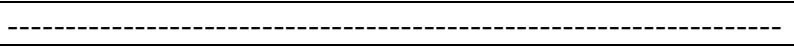 & Quick-witted \\
\hline Attentive & 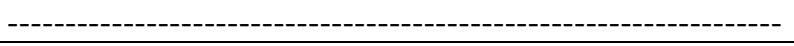 & Dreamy \\
\hline Incompetent & 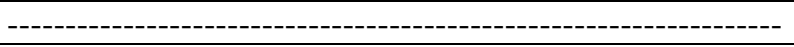 & Proficient \\
\hline \multicolumn{3}{|c|}{ ALERTNESS RATING } \\
\hline \multicolumn{2}{|c|}{ DAY 1 AFTER BREAKFAST } & CHILD 3 \\
\hline \multicolumn{2}{|c|}{ RATINGS COMPLETED BY (please circle) } & ADULT 1 / ADULT 2 \\
\hline \multicolumn{3}{|c|}{$\begin{array}{l}\text { On each of the following lines please draw a cross between the two extremes which } \\
\text { best represents how your child is feeling now. }\end{array}$} \\
\hline Drowsy & -------------------------------------------------------------------------- & Alert \\
\hline Strong & 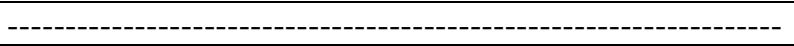 & Feeble \\
\hline Muzzy & 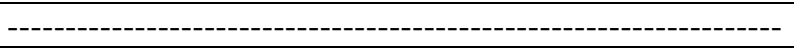 & Clear-headed \\
\hline Co-ordinated & -------------------------------------------------------------------------- & Clumsy \\
\hline Lethargic & 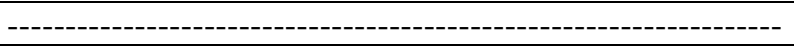 & Energetic \\
\hline Mentally-slow & 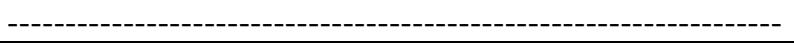 & Quick-witted \\
\hline Attentive & ------------------------------------------------------------------------- & Dreamy \\
\hline Incompetent & ------------------------------------------------------------------------ & Proficient \\
\hline \multicolumn{2}{|c|}{ DAY 1 AFTER BREAKFAST } & CHILD 4 \\
\hline \multicolumn{2}{|c|}{ RATINGS COMPLETED BY (please circle) } & ADULT 1 / ADULT 2 \\
\hline \multicolumn{3}{|c|}{$\begin{array}{l}\text { On each of the following lines please draw a cross between the two extremes which } \\
\text { best represents how your child is feeling now. }\end{array}$} \\
\hline Drowsy & 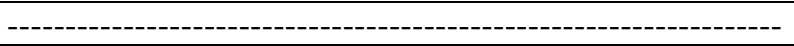 & Alert \\
\hline Strong & 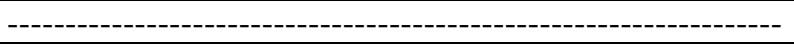 & Feeble \\
\hline Muzzy & ------------------------------------------------------------------------ & Clear-headed \\
\hline Co-ordinated & 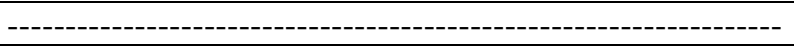 & Clumsy \\
\hline Lethargic & 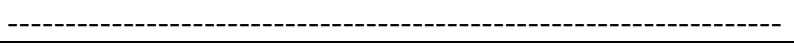 & Energetic \\
\hline Mentally-slow & 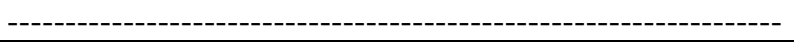 & Quick-witted \\
\hline Attentive & 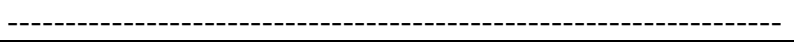 & Dreamy \\
\hline Incompetent & 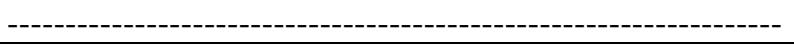 & Proficient \\
\hline
\end{tabular}

\begin{tabular}{|c|c|c|}
\hline \multicolumn{3}{|c|}{ ALERTNESS RATING } \\
\hline \multicolumn{2}{|c|}{ DAY 1 AFTER BREAKFAST } & CHILD 5 \\
\hline \multicolumn{2}{|c|}{ RATINGS COMPLETED BY (please circle) } & ADULT 1 / ADULT 2 \\
\hline \multicolumn{3}{|c|}{$\begin{array}{l}\text { On each of the following lines please draw a cross between the two extremes which } \\
\text { best represents how your child is feeling now. }\end{array}$} \\
\hline Drowsy & 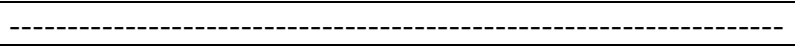 & Alert \\
\hline Strong & 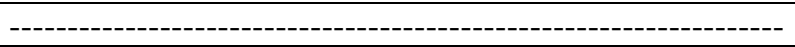 & Feeble \\
\hline Muzzy & 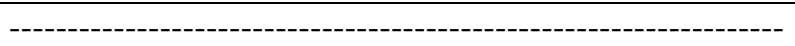 & Clear-headed \\
\hline Co-ordinated & ------------------------------------------------------------------------------ & Clumsy \\
\hline Lethargic & 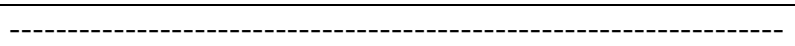 & Energetic \\
\hline Mentally-slow & ---------------------------------------------------------------------------------- & Quick-witted \\
\hline Attentive & --------------------------------------------------------------------------- & Dreamy \\
\hline Incompetent & 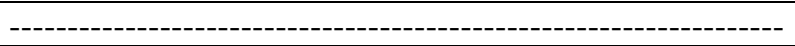 & Proficient \\
\hline
\end{tabular}

\section{Copyrights}

Copyright for this article is retained by the author(s), with first publication rights granted to the journal.

This is an open-access article distributed under the terms and conditions of the Creative Commons Attribution license (http://creativecommons.org/licenses/by/4.0/). 